\title{
The effect of two feedback strategies on EFL writing quality from the perspective of syntactic complexity
}

\author{
Blanka Pojslová
}

\begin{abstract}
This paper aims to present the results of the study investigating the efficacy of computer-mediated feedback on EFL learners' performance in writing with regard to syntactic complexity as an aspect of writing quality. The research design of the study took the form of a pre-test/post-test quasi-experiment with two comparison groups which received different treatments. The participants of the study were 65 advanced EFL learners of English for Specific Purposes who were divided into two groups. The first group (33 students) was provided with the treatment in the form of teacher-only multiple-draft feedback while the other group (32 students) was given the treatment in the form of combined peer-teacher multiple-draft feedback.

The study investigated if there were any differences in syntactic complexity at a global, a clausal and a phrasal level between pre-test and post-test and what the implications of these differences for writing quality were in individual groups together with comparing the differences between the groups. Syntactic complexity was automatically measured by selected indices of L2 Syntactic Complexity Analyzer (Lu, 2010), a freely available natural language processing tool. The study yielded four major findings. First, the results indicate some statistically significant improvements in writing quality with regard to syntactic complexity and with respect to the proficiency level of the participants in both groups. Second, syntactic complexity developed in both groups between the pre-test and post-test, but with no significant difference in post-test performance between the comparison groups. Third, teacher-only feedback seems to be more effective at the global and phrasal level of syntactic complexity while combined peer-teacher feedback is more effective at the clausal level. Finally, teacher-only feedback contributed to more homogenous post-test writing production.
\end{abstract}

Key words: computer-mediated feedback, writing quality, syntactic complexity, peer feedback, foreign language writing

\section{Introduction}

Teaching second or foreign language writing usually involves feedback provision. Feedback may be defined as information given to the learner on their writing with the objective of improving their performance (Ur, 1996, p. 242). Feedback can be classified as either summative or formative. While summative feedback focuses on writing as a product, formative feedback assists learners in developing their writing skills (Hyland, 2006, p. 83). Formative feedback is usually provided on structure, organisation, style, and presentation, and is often supplemented by written corrective feedback which refers to indications of the learner's non-target-like use of the target language (Gass, 1997; Schachter, 1991). Formative feedback is also more process-oriented, as it is usually given on multiple drafts, and includes sug- 
gested revisions. In genre-oriented classes, feedback helps students master new literary practices and develop genre knowledge, thus introducing novice writers to new discourse communities (Li, 2006).

The feedback (the response to a student's writing) can follow various techniques or strategies. The responder may give direct, indirect, or metalinguistic feedback by providing the correct form (direct feedback), indicating an error without the correction (indirect feedback) or indicating it using an error code or a brief metalinguistic explanation of the error (Ellis, 2009, p. 98). Hyland (2007, p. 180) recommends four feedback techniques: commentary, cover sheets, minimal marking, and taped comments. Feedback can be provided in a traditional pen-and-pencil mode, but in many educational settings, especially at universities, computer-mediated feedback through classroom/learning management systems has become widespread. Computer-mediated feedback (e-feedback) can be delivered synchronously (typically through online chats), or asynchronously, in the form of emails, discussion board messages, comments/track changes in MS Word, audio feedback, or commentary videos.

Feedback can be further distinguished by its source, as either teacher or peer feedback. While teacher feedback limits the learner's role to the role of a writer, peer feedback makes learners play a dual role as both writers and reviewers, and allows them to benefit as both feedback givers and receivers. As peer feedback receivers, learners can develop their critical thinking and autonomy (Miao, 2006), gain confidence, negotiate multiple perspectives (Ferris, 2003), and have a real sense of audience (Mangelsdorf, 1992). Peer feedback is usually more appropriate for a learner's developmental level, and is often easier for them to understand, giving them more information for subsequent revisions (Allison \& Ng, 1992; Chaudron, 1984).

Since providing peer feedback is a two-way process, peer feedback givers can also benefit from the process. After engaging in peer-review, EFL and ESL students have self-reported increased awareness of the importance of the global aspects of their writing (Berg, 1999; Min, 2005; Miao, Badger, \& Zhen, 2006). Feedback givers also critically self-evaluate their own writing to make appropriate revisions (Rollinson, 2005). Learners who only provided (but did not receive) peer feedback improved significantly more in writing quality than those who only received (but did not give) peer feedback, especially at the macro-level of their writing (Lundstorm \& Baker, 2009).

In the 1980s and 1990s, several studies questioned the effectiveness of feedback, especially written corrective feedback. But more recent empirical research suggests that feedback leads to improved writing. This improvement seems to be more likely if the feedback is directly related to previous instruction in the class, and if indirect feedback methods are used (Hyland and Hyland, 2006, pp. 84-86). 
Therefore, prior to being given feedback on their writing, learners should receive considerable input on organisational features of the target genre and appropriate language for that genre. Then, ensuing feedback should reinforce what has been taught by referring back to the class input. In this context, indirect feedback techniques can be more effective, and can help the students develop long-term editing and proofreading skills (Hyland, 2007, p. 185).

The current study investigates two feedback strategies within the process-genre framework of teaching writing and their effect on writing quality from the perspective of syntactic complexity. These feedback treatments aim to be as individualised as possible, and strive to conform to good practice in that they are timely, specific, balanced, multiple-draft, and appropriate (Ferris, 2003, pp. 118131). The two feedback strategies are similar in that they combine several feedback techniques to respond to individual learner's needs. Both are provided in a computer-mediated setting, in an asynchronous mode. The difference between the strategies lies in the source of feedback. The first is provided by only the teacher, while the second combines peer and teacher feedback on subsequent drafts of the same text. Learner corpora of pre-test and post-test essays were collected and analysed to find out how these different feedback strategies affected the syntactic complexity, which is considered a key aspect of writing quality (Crossley, 2020).

\subsection{Writing quality and syntactic complexity}

Writing quality can be captured by three complementary dimensions - complexity, accuracy, and fluency - or CAF for short (Housen, Kuiken, \& Vedder, 2012; Norris \& Ortega, 2009). In L2 writing research, complexity measures might serve as indicators for L2 writing quality (Ortega, 2003; Wolfe-Quintero et al., 1998). In the context of second or foreign language writing, complexity is usually understood as linguistic rather than cognitive complexity. Linguistic complexity, which is characterised as the degree of sophistication and variety of a learner's production (Ellis, 2003, p. 340), is one of the dimensions in the Bulté and Housen taxonomic model of L2 complexity (2012, p. 23). In this model, linguistic complexity can be studied at the level of the language system as a whole, or at the level of individual linguistic features across various domains or layers of language. One of those layers of language is syntax (Bulté \& Housen, 2014, p. 44).

Syntactic complexity as a component of linguistic complexity is broadly understood as the range of forms and the degree of sophistication of forms in a learner's language production (Ortega, 2003, p. 492). From the perspective of second or foreign language acquisition, syntactic complexity is an important construct, because the development of a learner's communicative competence also entails an increase in the range of syntactic structures they use, and their ability to use them 
appropriately in communication (Ortega, 2003). Crossley (2020) presents studies that show that higher L2 quality writing generally contains more complex syntactic features which have been operationalised based mainly on the length of production or the frequency of syntactic structures (p. 422). Norris \& Ortega (2009) proposed systematically investigating syntactic complexity in learners' production in three dimensions - at the global, the clausal, and the phrasal level (pp. 562564).

Global measures capture syntactic complexity from the perspective of the length of the production. They are gauged by dividing the total number of words by a chosen production unit - a clause, a sentence, or a T-unit. Table 1 shows a description of the relevant production units and structures used in this study. Global measures of syntactic complexity have been found to be predictive of, or to correlate positively with, L2 writing quality (Bulté \& Housen, 2014; Yang et al., 2015; $\mathrm{Li}, 2015)$. Also, longer production units have been found to correlate with a higher level of proficiency (Wolfe-Quintero et al., 1998; Ortega, 2003; Lu, 2011).

The measures at the clausal level capture syntactic complexity from the perspective of subordination and coordination. The amount of subordination is gauged by dividing the number of all clauses by a chosen production unit, while the amount of coordination is gauged by dividing the number of coordinate phrases by a chosen production unit. Some of these measures have been found to correlate with, or be predictive of, writing quality (Yang, 2015; Li, 2015), and are considered to be the most useful indices for measuring writing development at a beginning and intermediate level of proficiency (Bardovi-Harling, 1992; Lu, 2011; Casal \& Lee, 2019).

The phrasal dimension of syntactic complexity can be measured as the number of complex nominals per production unit, and as a mean length of clause. These measures have been found to be strong predictors of writing quality, or to correlate with it (Bulté \& Housen, 2014; Yang et al., 2015; Li, 2015; Kyle, 2018). They also discriminate between proficiency levels (Lu, 2011; Lu \& Ai, 2015). At the advanced level, complexification prevails at the phrasal level, while complexification at the clausal level is subdued or plateaus (Lu, 2011; Byrnes \& Norris, 2010; Norris \& Ortega, 2009; Ortega, 2003).

\subsection{Literature review}

Studies exploring the effect on writing quality of computer-mediated feedback provided asynchronously are relatively rare. These studies usually compare or study the efficacy of various techniques, modes, or sources of feedback. Shang (2017) compared how asynchronous peer e-feedback and synchronous corrective feedback affected the syntactic complexity of EFL writing. The study revealed 
Tab. 1: Definitions of Relevant Production Units and Structures

\begin{tabular}{|c|c|c|}
\hline Production unit & Definition & Example \\
\hline Sentence & $\begin{array}{l}\text { A group of words punctuated with } \\
\text { a sentence-final punctuation mark, usually } \\
\text { a period, exclamation mark, or question } \\
\text { mark (Hunt, 1965). }\end{array}$ & I went running today. \\
\hline Clause & $\begin{array}{l}\text { A structure with a subject and a finite verb, } \\
\text { including independent, adjective, adverbial, } \\
\text { and nominal clauses, but not non-finite } \\
\text { verb phrases (Hunt, 1965; Polio, 1997). }\end{array}$ & $\begin{array}{l}\text { I ate pizza } \\
\text { because I was hungry. }\end{array}$ \\
\hline T-unit & $\begin{array}{l}\text { An independent clause and any clauses } \\
\text { dependent on it. }\end{array}$ & $\begin{array}{l}\text { I ate pizza. } \\
\text { l ate pizza because I was hungry. }\end{array}$ \\
\hline Dependent clause & $\begin{array}{l}\text { A finite clause that is an adverbial, } \\
\text { adjective, or nominal clause. }\end{array}$ & I ate pizza because I was hungry. \\
\hline Coordinate phrases & $\begin{array}{l}\text { Adjective, adverb, noun, and verb phrases } \\
\text { connected by coordination conjunction. }\end{array}$ & She eats pizza and smiles \\
\hline Complex nominals & $\begin{array}{l}\text { i. Nouns with modifiers } \\
\text { ii. Nominal clauses } \\
\text { iii. Gerunds and infinitives that function as } \\
\text { subjects }\end{array}$ & $\begin{array}{l}\text { i. red car } \\
\text { ii. I know that she is hungry. } \\
\text { iii. Running is invigorating. }\end{array}$ \\
\hline
\end{tabular}

Adapted from Lu (2010, pp. 7-13; 2011, pp. 44-45)

significant positive relationships between both modes of feedback and aspects of syntactic complexity. Shang found that the asynchronous peer e-feedback resulted in a higher mean writing score than the synchronous feedback, though not significantly.

Studies investigating the effect of asynchronous computer-mediated feedback on writing quality as assessed by human raters are also scarce. AbuSeileek \& Abualsha'r (2014) compared three experimental groups and one control group, and found that students in the experimental groups who received any kind of peer efeedback (track changes, recast, or metalinguistic feedback) improved their posttest writing scores significantly more than students in the control group, who received no corrective feedback. The group which received the track-changes feedback significantly outperformed the remaining two experimental groups. Pham et al. (2020) investigated the effect of peer e-feedback on global and local features of EFL academic writing. They concluded that after the feedback, post-test writing was significantly better with regard to both global (organisation, flow of ideas, examples) and local aspects (grammar accuracy, structures, punctuation, vocabulary).

Motallebzadeh et al. (2011) explored the effect of teacher and peer e-feedback on writing quality, and compared it with the effect of traditional pen-and-pencil teacher feedback (control group). The results revealed that both experimental 
groups outperformed the control group, and that peer e-feedback seemed to be more effective in improving EFL writing quality than teacher e-feedback. Al-Olimat \& Abu Seillek (2015) compared the effect of three different e-feedback strategies - teacher-only, peer-only, and combined peer-teacher - on EFL writing quality. They found that all three experimental groups achieved significantly better writing scores than the control group, who had no feedback provision. The group with combined peer-teacher e-feedback significantly outperformed the remaining two experimental groups.

To the best of our knowledge, no study has been conducted to investigate and compare the efficacy of the treatments in the form of teacher-only and combined peer-teacher feedback on syntactic complexity as an aspect of writing quality from the global, clausal and phrasal perspective. In order to fill in the gaps in the current research, this study was conducted.

\section{Method}

\subsection{Research questions}

The present study explores the effects of two different feedback strategies on syntactic complexity as an aspect of writing quality. The study addresses the following three research questions:

RQ1: How did teacher-only three-draft e-feedback affect participants' writing quality, as measured by selected indices of syntactic complexity?

RQ2: How did combined peer-teacher three-draft e-feedback affect participants' writing quality, as measured by selected indices of syntactic complexity?

RQ3: Is there any statistically significant difference in post-test writing quality between the comparison groups, as measured by selected indices of syntactic complexity?

\subsection{Operationalisation of syntactic complexity}

In line with the theoretical framework outlined above, in this study a set of measures generated by L2 Syntactic Complexity Analyzer (Lu, 2010) was used to measure syntactic complexity of student writing. L2 Syntactic Complexity Analyzer (L2SCA) is a computer program designed to analyse the syntactic complexity of English writing samples and capturing three dimensions of syntactic complexity (Wolfe-Quintero et al., 1998; Ortega, 2003; Ortega, 2009) - at the global, clausal and phrasal level. L2SCA generates 14 indices of syntactic complexity whereas their higher values are associated with higher degrees of syntactic complexity (Lu, 2017, p. 502). 
In the present study, five indices of syntactic complexity generated by L2SCA were used. These selected indices have been found to be predictive of, or to correlate with, L2 writing quality scores given by human raters. Table 2 presents the definitions of the selected L2SCA indices used in this study, with the dimensions of syntactic complexity they gauge, and a study or studies proving that the index is predictive of, or correlates with, L2 writing quality.

Tab. 2: Syntactic complexity indices used

\begin{tabular}{|c|c|c|c|}
\hline Index & Code & Definition & Study \\
\hline \multicolumn{4}{|l|}{ Global level } \\
\hline $\begin{array}{l}\text { Mean length of } \\
\text { T-unit }\end{array}$ & MLT & $\begin{array}{l}\text { he number of words divided by the } \\
\text { number of T-units. }\end{array}$ & $\begin{array}{l}\text { Li (2015); Yang et al. (2015); } \\
\text { Bulté \& House (2014) }\end{array}$ \\
\hline \multicolumn{4}{|c|}{ Clausal level - subordination } \\
\hline $\begin{array}{l}\text { Dependent } \\
\text { clauses per clause }\end{array}$ & $\mathrm{DC} / \mathrm{C}$ & $\begin{array}{l}\text { The number of dependent clauses } \\
\text { divided by the number of clauses. }\end{array}$ & Li (2015) \\
\hline \multicolumn{4}{|l|}{ Phrasal level } \\
\hline $\begin{array}{l}\text { Coordinate } \\
\text { phrases per clause }\end{array}$ & $\mathrm{CP} / \mathrm{C}$ & $\begin{array}{l}\text { The number of coordinated phrases } \\
\text { divided by the number of clauses. }\end{array}$ & $\begin{array}{l}\text { Yang et al. (2015); Kyle (2018); } \\
\text { Kim \& Crossley (2018) }\end{array}$ \\
\hline $\begin{array}{l}\text { Mean length of } \\
\text { clause }\end{array}$ & MLC & $\begin{array}{l}\text { The number of words divided by the } \\
\text { number of clauses. }\end{array}$ & $\begin{array}{l}\text { Bulté \& House (2014); Yang et al. } \\
\text { (2015); Kim \& Crossley (2018); } \\
\text { Kyle (2018); Li (2015); }\end{array}$ \\
\hline $\begin{array}{l}\text { Complex nominals } \\
\text { per clause }\end{array}$ & $\mathrm{CN} / \mathrm{C}$ & $\begin{array}{l}\text { The number of complex nominals divided } \\
\text { by the number of clauses. }\end{array}$ & $\begin{array}{l}\text { Li (2015); Yang et al. (2015); Kim } \\
\text { \& Crossley (2018) }\end{array}$ \\
\hline
\end{tabular}

Adapted from Lu (2011, 2017) and Casal \& Lee (2019)

\subsection{Participants and context of the study}

The participants were 65 undergraduate EFL students drawn from four intact classes (out of a total of fourteen classes) of a 13-week semester course of English for Specific Purposes (ESP). The four-semester ESP course series develops students' communicative competence in Business English with a target CEFR level of C1. All four language skills are developed side by side throughout the course series, but in each semester a different skill is emphasized. The course in which the study was carried out familiarises the students with selected features of academic writing which are relevant to their needs. The population of the study was 279 students. It was homogenous in terms of language proficiency, as the students have to accomplish three prerequisite courses that end in standardised pro-achievement tests. Table 3 shows a detailed description of the participants' profiles.

\subsection{Research design}

The research was designed as quasi-experimental since randomisation of the participants to groups was impossible due to institutional constraints. The quasi- 
Tab. 3: Participant profiles

\begin{tabular}{|l|l|l|l|}
\hline & & Group 1 & Group 2 \\
\hline \multirow{2}{*}{ Gender } & Male & 17 & 11 \\
& Female & 16 & 21 \\
\hline \multirow{2}{*}{ Age } & Mean & 21.4 & 21.4 \\
& Range & $21-24$ & $21-23$ \\
\hline L1 background & Czech & 21 & 15 \\
& Slovak & 11 & 17 \\
\hline English proficiency test (CEFR based) & Other & 1 & 0 \\
\hline Course test 1 results & Mean Score (SD) & $59.3(11.3)$ & $61.8(14.3)$ \\
\hline Course test 2 results & Mean Score (SD) & 54.7 (6.5) & $56.3(7.4)$ \\
\hline Course test 3 results & Mean Score (SD) & 44.5 (5.9) & 46.8 (5.6) \\
\hline
\end{tabular}

English proficiency test: B1: 42-63; B2: 64-86; C1: 87-95

Course test 1+2: Max.: 75pts. / Min. to pass: 45pts.

Course test 3: Max.: 65pts. / Min. to pass: 39pts.

experiment took the form of a pre-test/post-test study with two comparison groups that received different feedback treatments. The comparison groups were formed naturally by two intact seminar groups which were chosen by the participants depending on their schedule preferences, and the allocation of two intact classes to the individual comparison groups was done randomly.

The research was conducted over the 13 weeks of the spring semester and all four groups were taught by the same teacher who was also the researcher. In the first six weeks, students were introduced to the features of academic writing and the genre of the problem-solution essay $(t 1)$. After being given this input, students wrote the pre-test essays, on which they received three-draft e-feedback ( $t 2)$. In the following five weeks ( $t 3)$, the comparison groups received treatment in the form of two feedback strategies. Group 1 received teacher-only e-feedback on all three drafts of the essay, while Group 2 received peer e-feedback on the first draft and teacher e-feedback on the second and third drafts of their essays. After the treatments, both groups wrote a post-test essay (t4). Table 4 shows the research design.

\section{$2.5 \quad$ Feedback Treatments}

The main difference between the two groups was the source of the feedback they received. Group 1 received teacher-only e-feedback, while Group 2 received combined peer-teacher e-feedback. In each group, various feedback techniques were combined to respond to individual students' needs. Teacher e-feedback on the first and second drafts in Group 1 took the form of indirect coded feedback 
Tab. 4: Research design

\begin{tabular}{|c|c|c|}
\hline & Group 1 (N=33 participants) & Group 2 ( $N=32$ participants) \\
\hline$t 1$ & \multicolumn{2}{|c|}{$\begin{array}{l}\text { Face-to-face input on the features of academic English and the genre of a problem-solution } \\
\text { essay. }\end{array}$} \\
\hline$t 2$ & \multicolumn{2}{|c|}{$\begin{array}{c}\text { PRE-TEST } \\
1^{\text {st }} \text { Draft of the problem-solution essay }\end{array}$} \\
\hline \multirow[t]{8}{*}{ t3 } & \multicolumn{2}{|c|}{ TREATMENT } \\
\hline & \multirow{2}{*}{$\begin{array}{l}\text { Teacher e-feedback } \\
\text { on the } 1^{\text {st }} \text { draft }\end{array}$} & $\begin{array}{l}\text { Face-to-face training on peer e-feedback } \\
\text { provision }\end{array}$ \\
\hline & & $\begin{array}{l}\text { Peer e-feedback } \\
\text { on the } \mathbf{1}^{\text {st }} \text { draft (by } 3 \text { peers) }\end{array}$ \\
\hline & $\begin{array}{l}1^{\text {st }} \text { revision based on } \\
\text { teacher e-feedback }\end{array}$ & $\begin{array}{l}1^{\text {st }} \text { revision based on } \\
\text { peer e-feedback }\end{array}$ \\
\hline & Submission of the $2^{\text {nd }}$ draft & Submission of the $2^{\text {nd }}$ draft \\
\hline & Teacher e-feedback on the $2^{\text {nd }}$ draft & Teacher e-feedback on the $2^{\text {nd }} \mathbf{d r a f t}$ \\
\hline & $\begin{array}{l}2^{\text {nd }} \text { revision based on } \\
\text { teacher e-feedback }\end{array}$ & $\begin{array}{l}2^{\text {nd }} \text { revision based on } \\
\text { teacher e-feedback }\end{array}$ \\
\hline & $3^{\text {rd }}$ draft $=$ Final version & $3^{\text {rd }}$ draft = Final version \\
\hline$t 4$ & \multicolumn{2}{|c|}{$\begin{array}{l}\text { POST-TEST } \\
\text { Post-test problem-solution essay assigned. }\end{array}$} \\
\hline
\end{tabular}

covering five broad categories: organisation; mechanics; academic style; vocabulary; and grammar. Using different colour codes linked to these categories, the teacher highlighted problematic language in the students' texts. Along with the coded feedback, the teacher provided the students with MS Word comments on genre-relevant problems, as the genre of the problem-solution essay was new to them. Both the comments and coded feedback were sometimes supplemented by links to external sources that offered a fuller explanation or metalinguistic information. The teacher also added general evaluative commentary, to inform the writer about the extent to which he/she met general expectations. Finally, the teacher completed a checklist with a 4-point scale for each version, to inform the writer about the extent to which he/she met specific expectations with regard to essay structure, organisation, and academic style.

Teacher feedback on the third draft took the form of direct feedback in revision mode, with occasional MS Word comments and the completed checklist. The teacher also assessed the third version of the text with the final exam assessment criteria using an analytical scale for task completion, organisation, vocabulary, and grammar. The teacher also evaluated the writer's effort to incorporate received feedback in their writing. Finally, the teacher added a general evaluative commentary, to summarise the writer's achievement and potential areas for improvement. 
Group 2 also received three-draft e-feedback on their essays. The feedback on the first draft was provided by three peers randomly and anonymously assigned to each essay by the online application Peer Review, which seamlessly handled the logistics of essay exchanges among the students. The number of peer feedback providers was determined to three peers to compensate for lower number of feedback comments from peers as compared to teacher's (Hublova, 2016; p. 141). Before providing peer e-feedback, the students in Group 2 were given a 45-minute training session to familiarise themselves with the rationale and the techniques of peer feedback. Peers were trained to provide their e-feedback in a similar manner to the teacher e-feedback, using colour codes to highlight problematic language in the text, and MS Word comments to give feedback on the essay structure, organisation, and content. Furthermore, the students completed the same checklist as the teacher, indicating the extent to which the expectations were met. Feedback on the second and third drafts of Group 2 essays was provided by the teacher in the same manner as in Group 1. Appendix A presents an example of teacher efeedback on the first and second draft, and Appendix B presents an example of peer e-feedback on the first draft.

\subsection{Data collection}

Data collection took place over six weeks (t2-t4). During that time, 65 pre-test essays and 65 post-test essays were collected (33 in Group 1; 32 in Group 2). The pre-test and post-test essays were compiled in two pre-test corpora and two posttest corpora. Figures 1 and 2 show the prompts used to elicit the corpora, which had been previously piloted on a similar population.

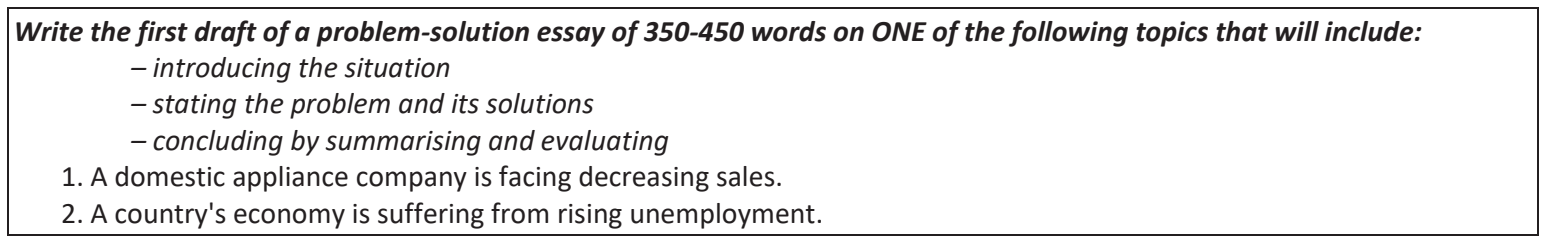

Fig. 1: Prompt for eliciting pre-test learner corpora

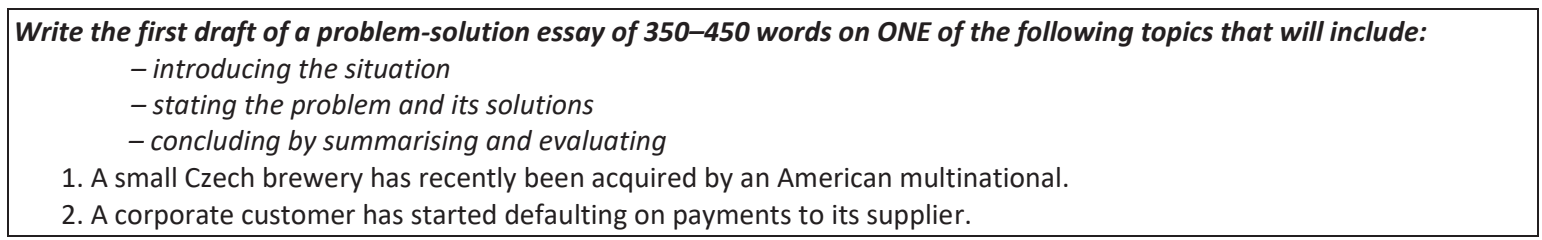

Fig. 2: Prompt for eliciting post-test learner corpora

The prompts do not include explicit genre, stylistic, and formal requirements, because the participants were familiar with them from the contact classes. The participants were free to choose either of the topics, depending on their preferences 
and content knowledge, with the hope that this would increase their interest in the writing (Nation \& Laufer, 1995).

\subsection{Data analysis}

Pre-test and post-test corpora were processed by L2 syntactic complexity analyser (L2SCA) to obtain the values of selected indices for each essay in two pre-test (Group 1 and Group 2) and two post-test (Group 1 and Group 2) corpora. Selected data were processed by SPSS Version 25 for statistical analysis. As the variables were not normally distributed, nonparametric tests were used. The Wilcoxon signed-rank test was applied to examine differences in syntactic complexity between pre-test and post-test in both groups. The Mann-Whitney U test was applied to investigate differences in syntactic complexity of post-test production between Group 1 and Group 2, which received different feedback treatments.

The level of statistical significance expressed by $p$-value was interpreted as statistically significant for $p$-value less than 0.05 . In order to measure the magnitude of the experimental effect or the strength of the difference between groups, the effect size was calculated asPearson $r$ and interpreted as small for $r$ of $0.1-0.29$, as medium for $r$ of $0.3-0.49$, and as large for $r$ greater than 0.5 (Cohen, 1988, p. 25). Finally, to show and compare the extent of relative variability in relation to the mean of the population, the coefficient of variation $(\mathrm{CV})$ was calculated as the ratio of the standard deviation to the mean and expressed as a percentage. The higher the coefficient of variation, the greater the level of dispersion around the mean is.

\section{Findings}

\subsection{Syntactic complexity in Group 1 with teacher-only e-feedback}

The first research question investigated how teacher-only three-draft e-feedback affected participants' writing quality, as measured by selected L2SCA indices of syntactic complexity. Table 5 presents descriptive statistics (means, standard deviations, and coefficients of variation) for selected indices of syntactic complexity for 33 pre-test and 33 post-test essays in Group 1 with teacher-only e-feedback.

Table 6 shows whether the differences in the indices of syntactic complexity in Group 1 between pre-test and post-test were statistically significant, and how effective these changes were, as measured by the effect size $r$.

The statistics revealed that the mean values of all the indices increased between the pre-test and post-test. The results of the Wilcoxon test then showed that these changes were statistically significant for the indices of Mean length of T-unit $(Z=$ -3.046; $p=0.002 ; r=0.5)$, Mean length of clause $(Z=-2.725 ; p=0.005 ; r=0.5)$, 
Tab. 5: Descriptive statistics for selected SCA indices of syntactic complexity in Group 1

\begin{tabular}{|l|c|r|r|r|r|r|c|}
\hline & & \multicolumn{3}{|c|}{ Pre-test } & \multicolumn{3}{c|}{ Post-test } \\
\cline { 3 - 8 } Index & Code & \multicolumn{1}{|c|}{ Mean } & \multicolumn{1}{|c|}{ SD } & CV (\%) & \multicolumn{1}{|c|}{ Mean } & \multicolumn{1}{c|}{ SD } & CV (\%) \\
\hline Mean length of T-unit & MLT & 16.6822 & 2.7523 & 16.50 & 18.0855 & 2.6630 & 14.72 \\
Dependent clauses per clause & DC/C & 0.2814 & 0.0881 & 31.31 & 0.2815 & 0.0971 & 34.49 \\
Coordinate phrases per clause & CP/C & 0.3473 & 0.1227 & 35.32 & 0.3556 & 0.1412 & 39.69 \\
Mean length of clause & MLC & 11.9058 & 1.4632 & 12.29 & 12.9870 & 1.8465 & 14.22 \\
Complex nominals per clause & $\mathrm{CN} / \mathrm{C}$ & 1.5212 & 0.3857 & 25.35 & 1.7007 & 0.3726 & 21.91 \\
\hline
\end{tabular}

Tab. 6: Results of Wilcoxon signed-rank test for changes in indices of syntactic complexity in Group 1

\begin{tabular}{l|c|c|c|l|}
\hline Index & Code & $Z$ & $p$ & $r$ \\
\hline Mean length of T-unit & $\mathrm{MLT}$ & -3.046 & 0.002 & 0.5 \\
Dependent clauses per clause & $\mathrm{DC} / \mathrm{C}$ & -0.045 & 0.972 & 0 \\
Coordinate phrases per clause & $\mathrm{CP} / \mathrm{C}$ & -0.205 & 0.846 & 0 \\
Mean length of clause & $\mathrm{MLC}$ & -2.725 & 0.005 & 0.5 \\
Complex nominals per clause & $\mathrm{CN} / \mathrm{C}$ & -2.225 & 0.025 & 0.4 \\
\hline
\end{tabular}

and Complex nominals per clause $(Z=-2.225 ; p=0.025 ; r=0.4)$, with large (Mean length of T-unit, Mean length of clause) and medium (Complex nominals per clause) effect size. The coefficients of variation decreased for the indices of Mean length of T-unit and Complex nominals per clause, and increased for the indices of Dependent clauses per clause, Coordinate phrases per clause, and Mean length of clause.

\subsection{Syntactic complexity in Group 2 with combined peer-teacher e-feedback}

The second research question investigated how combined peer-teacher three-draft e-feedback affected participants' writing quality, as measured by the indices of syntactic complexity. Table 7 presents descriptive statistics (means, standard deviations, and coefficients of variation) for selected indices of syntactic complexity for 32 pre-test and 32 post-test essays in Group 2 which received combined peerteacher e-feedback.

Tab. 7: Descriptive statistics for selected SCA indices of syntactic complexity in Group 2

\begin{tabular}{|l|c|c|c|c|r|r|c|}
\hline \multirow{2}{*}{ Index } & \multirow{3}{*}{ Code } & \multicolumn{3}{|c|}{ Pre-test } & \multicolumn{3}{c|}{ Post-test } \\
\cline { 3 - 8 } & Mean & SD & CV (\%) & Mean & SD & CV (\%) \\
\hline Mean length of T-unit & MLT & 17.328 & 2.3858 & 13.77 & 17.1108 & 2.852 & 16.67 \\
Dependent clauses per clause & DC/C & 0.2909 & 0.0996 & 34.24 & 0.2445 & 0.0895 & 36.61 \\
Coordinate phrases per clause & CP/C & 0.3431 & 0.1419 & 41.37 & 0.3647 & 0.2089 & 57.28 \\
Mean length of clause & MLC & 12.1044 & 1.6820 & 13.90 & 12.7963 & 2.1292 & 16.64 \\
Complex nominals per clause & CN/C & 1.5564 & 0.3084 & 19.82 & 1.6521 & 0.4503 & 27.26 \\
\hline
\end{tabular}


Table 8 shows whether the differences in the indices of syntactic complexity in Group 2 between pre-test and post-test were statistically significant, and how effective these changes were, as measured by the effect size $r$.

Tab. 8: Results of Wilcoxon signed-rank test for changes in indices of syntactic complexity in Group 2

\begin{tabular}{l|c|c|c|c|}
\hline Index & Code & $Z$ & $p$ & $r$ \\
\hline Mean length of T-unit & MLT & -0.355 & 0.722 & 0.1 \\
Dependent clauses per clause & $\mathrm{DC} / \mathrm{C}$ & -2.356 & 0.018 & 0.4 \\
Coordinate phrases per clause & $\mathrm{CP} / \mathrm{C}$ & -0.411 & 0.681 & 0.1 \\
Mean length of clause & $\mathrm{MLC}$ & -1.627 & 0.104 & 0.3 \\
Complex nominals per clause & $\mathrm{CN} / \mathrm{C}$ & -0.898 & 0.369 & 0.2 \\
\hline
\end{tabular}

The statistics revealed that the mean values of three indices (Coordinate phrases per clause, Mean length of clause, Complex nominals per clause) increased between the pre-test and post-test. In comparison, the mean values of the two remaining indices (Mean length of T-unit, Dependent clauses per clause) decreased. The coefficients of variation increased for all the indices between pre-test and post-test. The results of the Wilcoxon test showed that these changes were not statistically significant, except for the significant decrease in the mean value of the index of Dependent clauses per clause $(Z=-2.356 ; p=0.018 ; r=0.4)$, with a medium effect size.

\subsection{Post-test differences between Group 1 and Group 2 with different feedback treatments}

The third research question investigated whether there was any difference between Group 1 and Group 2, which received different feedback treatments, in the quality of post-test writing production, as measured by the indices of syntactic complexity. The results of the Mann-Whitney $U$ test revealed that there was no significant difference in any of the five indices of syntactic complexity in participants' post-test production between the comparison groups. Table 9 presents the results of the Mann-Whitney test.

Tab. 9: Results of Mann-Whitney test for differences in the indices of syntactic complexity between Group 1 and Group 2 in post-test production

\begin{tabular}{|l|c|c|c|l|}
\hline Index & Code & $Z$ & $p$ & $r$ \\
\hline Mean length of T-unit & $\mathrm{MLT}$ & -1.581 & 0.114 & 0.2 \\
Dependent clauses per clause & $\mathrm{DC} / \mathrm{C}$ & -1.398 & 0.162 & 0.2 \\
Coordinate phrases per clause & $\mathrm{CP} / \mathrm{C}$ & -0.157 & 0.875 & 0 \\
Mean length of clause & $\mathrm{MLC}$ & -0.276 & 0.783 & 0 \\
Complex nominals per clause & $\mathrm{CN} / \mathrm{C}$ & -0.367 & 0.713 & 0 \\
\hline$p<0.05 ;$ two-tailed
\end{tabular}




\section{Discussion and Conclusion}

This study investigated the effect of two different feedback treatments on syntactic complexity, which is considered an aspect of the writing quality of advanced learners of English as a foreign language. Students received either asynchronous computer-mediated feedback given by the teacher on all three drafts of the same version of the text, or asynchronous computer-mediated feedback given by three peers on the first draft and by the teacher on the second and third draft. The effects of the treatments with regard to syntactic complexity were measured between the first draft of pre-test essays and the post-test essays. The results of the study indicate four major trends with regard to changes in the selected measures of syntactic complexity.

The first objective of this study was to investigate changes in the quality of EFL writing production measured by the indices of syntactic complexity in Group 1 after teacher-only e-feedback. The writing quality in this group improved at the global and phrasal level of syntactic complexity as the index of Mean length of Tunit at the global level, and the number of Complex nominals per clause, and Mean length of clause at the phrasal level increased significantly. This positive correlation between the length of production units and the number of complex nominals and writing quality have been proved by several studies (Bulté \& Housen, 2014; Yang et al., 2015; Li 2015). The improvements also correspond with participants' advanced level of proficiency, as complexification at the advanced level of proficiency takes place mainly at the global (Ortega, 2003; Wolfe-Quintero et al., 1998) and phrasal level of syntactic complexity (Lu, 2011; Ortega, 2003; Wolfe-Quintero et al., 1998). The effect size of these changes was medium for the index of Complex nominal per clause, and large for the indices Mean length of clause and Mean length of T-unit.

The increase in the remaining two indices of syntactic complexity was not significant. In terms of the relationship between subordination measured by the index of Dependent clauses per clause and proficiency level, the results also comply with findings that the role of subordination is subdued at the advanced level, as here phrasal-level complexification becomes the most pervasive means of syntactic complexity (Bardovi-Harling, 1992; Norris \& Ortega, 2009; Ortega 2003). It can be concluded that after the teacher-only e-feedback, participants produced almost the same number of clauses (a negligible and insignificant increase in the index of Dependent clause per clause). Still, the clauses they produced became significantly longer (a significant increase in the index of Mean length of clause), thus more complex. This corroborates with the findings of Crossley and McNamara (2014), who found that at the end of the study learners did not produce any more subordinated clauses, and in some cases they produced fewer. As for the index of Coordinate phrases per clause, Lu (2011) found that this index significantly 
increases from lower to higher levels of proficiency, but seems to plateau at the highest level. This corresponds with the findings of the present study, as after the teacher-only feedback, this aspect of syntactic complexity increased insignificantly, with zero effect size.

The second objective of this study was to investigate changes in the quality of EFL writing production measured by selected indices of syntactic complexity after combined peer-teacher e-feedback. An increase in the indices of syntactic complexity at the phrasal level would suggest improvements in writing quality with respect to proficiency level. However, in the present study these changes were not significant, with medium (Mean length of clause) and small effect size (Complex nominals per clause). Concerning the clausal level of syntactic complexity, the index of subordination decreased significantly. This result is corroborated by Lu (2011) , who found that the index of Dependent clauses per clause decreases significantly as a learner goes from lower to higher levels of proficiency. This result also confirms the findings that there is a trade-off between different dimensions of syntactic complexity as a learner's proficiency advances (Lu \& Ai, 2015). As in Group 1, the increase in the number of Coordinate phrases per clause in Group 2 reflects a positive change in terms of writing quality with regard to proficiency level, though it is statistically insignificant. At the global level, combined peer-teacher e-feedback affected the syntactic complexity in a rather unexpected way, as the length of the production decreased, though not significantly. This might be the result of a somewhat more careful approach taken by the students in Group 2 when writing their post-test essays. The teacher feedback, which students in Group 2 received on the second draft after the peer feedback on the first draft, was extensive with regard to organisation and genre, as these aspects had been addressed less by the peers (Pojslova, 2017). As a result, students in Group 2 may have felt hindered and took a more hesitant approach to writing their post-test essays, which might have been reflected in the decrease in the length of the production.

The third objective of this study was to examine the difference in post-test syntactic complexity as an aspect of writing quality between Group 1 (who received teacher-only e-feedback) and Group 2 (who received combined peer-teacher efeedback). The comparison of post-test production of both groups revealed no significant difference in any of the investigated indices of syntactic complexity. Nevertheless, two indices showed a difference in effect size between the groups, though the difference was small. The first one was Mean length of T-unit, in which Group 1 (teacher-only feedback) outperformed Group 2 (combined peer-teacher feedback) with regard to the length of production, but not significantly. The second one was Dependent clauses per clause which decreased more in Group 2, showing a small effect size, though again not significant. Both differences reflect the development between pre-test and post-test in the individual groups, and suggest 
that teacher-only feedback is more effective at the global and phrasal level, while combined peer-teacher feedback is more effective at the level of subordination.

Finally, the decrease in the coefficients of variation of the index of Mean length of T-unit and Complex nominals per clause in Group 1 suggests that teacher-only feedback contributes to more homogenous production at the global level, and with regard to the number of Complex nominals per clause, also at the phrasal level. The combined peer-teacher feedback, on the other hand, leads to more heterogeneous production, considering all indices under investigation at all levels of the syntactic complexity as the coefficients of variation increased after the treatment.

To conclude, both of the investigated feedback strategies seem to contribute to improvements in writing quality at the syntactic layer of linguistic complexity, but with different effects regarding the examined levels of syntactic complexity. Teacher-only e-feedback appears to be more effective at the global and phrasal level. In contrast, combined peer-teacher e-feedback appears to be more effective at the level of subordination, considering that the nature of complexification corresponds to the proficiency level of the participants. Moreover, teacher-only efeedback also leads to more homogenous post-test production with regard to the global and phrasal level of syntactic complexity.

The current study has several limitations, some of which might be addressed by further research. First, the numbers of participants in both groups were relatively low, so individual differences might have played a role that remained undetected. Second, the large-grained indices of syntactic complexity used in the study are not without criticism (Norris \& Ortega, 2009; Biber, Gray, \& Poonpon, 2011), so it would be useful to complement them with fine-grained indices of syntactic complexity at the clausal and phrasal level (Kyle \& Crossley, 2018) and establish a more precise syntactic classification of individual indices, especially the index Complex nominals per clause (Yang et al., 2015). Finally, the automatic evaluation of writing quality performed in this study might be triangulated by human ratings of the participants' written production along with qualitative research into the participants' perceptions of the respective feedback strategies.

\section{References}

AI, H., \& LU, X. (2013). A corpus-based comparison of syntactic complexity in nns and ns university students writing. In A. Díaz-Negrillo, N. Ballier, \& P. Thompson (Eds.), Automatic treatment and analysis of learner corpus data (pp. 249-264). Amsterdam: John Benjamins.

AbuSeileek, A., \& Abualsha'R, A. (2014). Using peer computer-mediated corrective feedback to support EFL learners' writing. Language Learning \& Technology, 18(1), 76-95. http://dx.doi.org/10125/ 44355.

Allison, D., \& NG, P. (1992). Developing text revision abilities. In M. Lau, \& M. J. Murphy (Eds.), Developing writing: Purposes and practice (pp. 106-130). Hong Kong: Institute of Language Education. 
Al-Olimat, S. I., \& ABUSEILEeK, A. F. (2015). Using computer-mediated corrective feedback modes in developing students' writing performance. Teaching English with Technology, 15(3), 3-30. https:// files.eric.ed.gov/fulltext/EJ1138425.pdf.

BARDovi-HARLIG, K. (1992). A second look at T-unit analysis: Reconsidering the sentence. TESOL Quarterly, 26, 390-395.

BERG, E. C. (1999). The effects of trained peer response on ESL students' revision types and writing quality. Journal of Second Language Writing, 8(3), 215-241. doi: 10.1016/S1060-3743(99)80115-5

Biber, D., Gray, B., \& Poonpon, K. (2011). Should we use characteristics of conversation to measure grammatical complexity in L2 writing development? TESOL Quarterly, 45, 5-35.

Bulté, B., \& Housen, A. (2012). Defining and operationalising L2 complexity. In A. HousEn, F. KuIKEN, \& I. VEDDER (Eds.), Dimensions of L2 performance and proficiency - Investigating complexity, accuracy and fluency in SLA (pp. 21-46). Amsterdam: John Benjamins.

Bulté, B., \& Housen, A. (2014). Conceptualising and measuring short-term changes in L2 writing complexity. Journal of Second Language Writing, 26, 42-65. doi.org/10.1016/j.jslw.2014.09.005

Byrnes, H., MAXIM, H. H., \& NorRIS, J. M. (2010). Realising advanced foreign language writing development in collegiate education: Curricular design, pedagogy, assessment [Monograph]. Modern Language Journal, 94(s1).

CASAL, J. E., LEE, J. J. (2019). Syntactic complexity and writing quality in assessed first-year L2 writing. Journal of Second Language Writing, 44, 51-62. https://doi.org/10.1016/j.jslw.2019.03.005.

Chaudron, C. (1984). The effects of feedback on students' composition revisions. RELC Journal 15(2), 1-14. doi.org/10.1177/00336882840150020

CoHEN, J. W. (1988). Statistical power analysis for the behavioral sciences (2nd edn). Hillsdale, New York: Lawrence Erlbaum Associates.

Crossley, S. A. (2020). Linguistic features in writing quality and development: An overview. Journal of Writing Research, 11(3), 415-443. https://doi.org/10.17239/jowr-2020.11.03.01.

FERris, D. (2014). Responding to student writing: Teachers' philosophies and practices. Assessing Writing, 19, 6-23.

Cumming, A., Kantor, R., \& Powers, D. E. (2002). Decision making while rating ESL/EFL writing tasks: A descriptive framework. The Modern Language Journal, 86(1), 67-96.

ELLIS, R. (2003). Task-based language learning and teaching. Oxford: Oxford University Press.

ELLIS, R. (2009). A typology of written corrective feedback types. ELT Journal, 63, 97-107. https:// doi.org/10.1093/elt/ccn023

FERRIS, R. D. (2003). Response to student writing: implications for second language students. Routledge: Taylor \& Francis Group.

GASS, S. (1997). Input, interaction, and the second language learner. Mahwah, NJ: Erlbaum.

HyLAND, K., \& HylAND, F. (2006). Feedback on second language students' writing. Language Teaching, 39(2), 83-101. DOI: 10.1017/S0261444806003399

Hyland, K. (2007). Second language writing. Cambridge: Cambridge University Press.

Housen, A., Kuiken, F., \& Vedder, I. (2012). Complexity, accuracy and fluency: Definitions, measurement and research. In A. Housen, F. KuIKEN, \& I. VedDer (Eds.), Dimensions of L2 performance and proficiency: complexity, accuracy, and fluency (pp. 1-20). Philadelphia: John Benjamins Pub. Co.

Hublová, G. (2016). Rozvoj diskurzivní competence v cizojazyčném akademickém psaní v anglickém jazyce $v$ důsledku účasti v e-learningovém kurzu (Disertační práce). Brno: Masarykova univerzita. Dostupné z https://is.muni.cz/auth/th/63926/pedf_d/DISERTACNI_PRACE.pdf 
Kyle, K., \& Crossley, S. A. (2018). Measuring Syntactic Complexity in L2 Writing Using Fine-Grained Clausal and Phrasal Indices. Modern Language Journal, 102 (2), 333-349. https://doi.org/10.1111/ modl.12468

LAUFER, B., \& NATION, P. (1995). Vocabulary size and use: Lexical richness in 12 written production. Applied Linguistics, 16 (3), 307-322. DOI: 10.1093/applin/16.3.307

LI, Y. (2006). Negotiating knowledge contribution to multiple discourse communities: A doctoral student of computer science writing for publication. Journal of Second Language Writing 15, 159-178.

LI, H. (2015). Relationship between measures of syntactic complexity and judgments of EFL writing quality. In Proceedings of 2015 Youth Academic Forum on Linguistics, Literature, Translation and Culture (pp. 216-222). Marietta, GA: American Scholars Press.

LU, X. (2010). Automatic analysis of syntactic complexity in second language writing. International Journal of Corpus Linguistics, 15, 474-496.

LU, X. (2011). A corpus-based evaluation of syntactic complexity measures as indices of college level ESL writers' language development. TESOL Quarterly, 45(1), 36-62.

LU, X., \& AI, H. (2015). Syntactic complexity in college-level English writing: Differences among writers with diverse L1 backgrounds. Journal of Second Language Writing, 29, 16-27.

LU, X. (2017). Automated measurement of syntactic complexity in corpus-based L2 writing research and implications for writing assessment. Language Testing, 34(4), 493-511. https://doi.org/10.1177/ 0265532217710675

Lundstrom, K., \& BAKer, W. (2009). To give is better than to receive: The benefits of peer review to the reviewer's own writing. Journal of Second Language Writing, 18(1), 30-43. DOI: 10.1016/ j.jslw.2008.06.002

MiAo, Y., BADGER, R., \& ZHEN, Y. (2006). A comparative study of peer and teacher feedback in a Chinese EFL writing class. Journal of Second Language Writing, 15(3), 179-200. DOI: 10.1016/ j.jslw.2006.09.004

MANGELSDoRf, K. (1992). Peer reviews in the ESL composition classroom: What do the students think? ELT Journal, 46(3) , 274-284. DOI: 10.1093/elt/46.3.274

Min, HT (2005). Training students to be successful peer reviewers. System, 33(2), 293-308. doi.org/ 10.1016/j.system.2004.11.003

Motallebzadeh, K., \& Amirabadi, S. (2011). Online Interactional Feedback in Second Language Writing: Through Peer or Tutor?. Theory and Practice in Language Studies, 1(5). 534-540. http:// dx.doi:10.4304/tpls.1.5.534-540.

NorRIS, J. M, \& ORTEGA, L. (2009). Towards an Organic Approach to Investigating CAF in Instructed SLA: The Case of Complexity, Applied Linguistics, 30(4), 555-578. doi.org/10.1093/applin/amp044

ORTEGA, L. (2003). Syntactic complexity measures and their relationship to L2 proficiency: A research synthesis of college-level L2 writing. Applied Linguistics, 24, 492-518. D0I: 10.1093/applin/ 24.4.492.

Pham, T. G., Lin, M., Trinh, V. Q., \& BuI, L. T. P. (2020). Electronic Peer Feedback. EFL Academic Writing and Reflective Thinking: Evidence From a Confucian Context. SAGE Open, 10 (1), 1-20. https:// doi.org/10.1177/2158244020914554.

PojSlova, B. (2017). Comparison of Students' Responsiveness to Teacher and Peer Feedback. In JANíKovÁ, V., \& HANUŠovÁ, S. (Eds.), Research in Foreign Language Teaching and Learning = Fremdsprachenlehrund Fremdsprachenlernforschung, (pp. 99-121). Brno: Masaryk University.

Rollinson, P. (2005). Using peer and teacher feedback on student writing. ELT Journal, 59(1), 23-30. DOI: $10.1093 /$ elt/cci003 
SHANG, H. (2017). An exploration of asynchronous and synchronous feedback modes in EFL writing. $J$ Comput High Educ, 29, 496-513. https://doi.or./10.1007/s12528-017-9154-0.

SCHACHTER, J. (1991). Corrective feedback in historical perspective. Interlanguage Studies Bulletin (Utrecht), 7(2), 89-102. https://doi.org/10.1177/026765839100700202.

TAGUCHI, N., CRAWFORD, W., \& WETZEL, D. Z. (2013). What linguistic features are indicative of writing quality? A case of argumentative essays in a college composition program. TESOL Quarterly, 47, 420-430. https://doi.org/10.1002/tesq.91.

UR P. (1996). A Course in Language Teaching, Practice and Theory. Cambridge: Cambridge University Press.

Wolfe-Quintero, K., INAGAKI, S., \& Kim, H. Y. (1998). Second language development in writing: Measures of fluency, accuracy, and complexity. Honolulu, HI: University of Hawai'i, Second Language Teaching and Curriculum Center. https://doi.org/10.1017/s0272263101263050.

YANG, W., LU, X., \& WEIGLE, S. A. (2015). Different topics, different discourse: Relationships among writing topic, measures of syntactic complexity, and judgments of writing quality. Journal of Second Language Writing, 28, 53-67.

\section{Author}

Ing. Mgr. Blanka Pojslová, e-mail: pojslova@econ.muni.cz

The author is an ESP instructor and Language Unit Head at the Faculty of Economics of Masaryk University in the Czech Republic. She teaches courses of Business English, academic writing and intercultural communication alongside developing study materials and assessment tools for these courses. She is currently undertaking her $\mathrm{PhD}$ research focusing on the role of feedback in the development of writing proficiency of ESP students. Her other research interests include the role of ICT tools in the facilitation of the learning process, and corpus linguistics, specifically analysing learner corpora to observe the FL acquisition process. 


\section{Appendix A}

\section{Teacher feedback on the first and second draft with the Final version of the text in Group 1.}

\begin{tabular}{|c|c|}
\hline 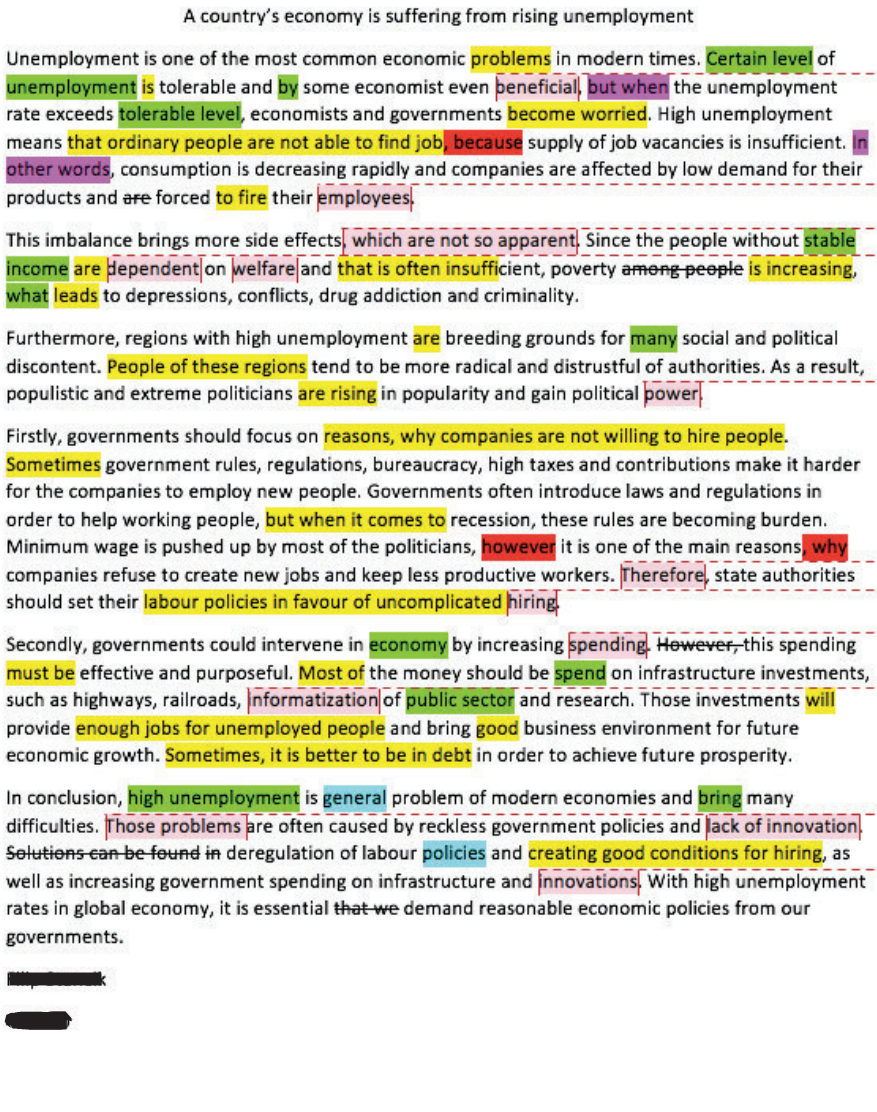 & $\begin{array}{l}\text { Isuggest joining } 2 \text { nd and } 3 r d \text { paragraph into one as they } \\
\text { might nicely describe why the situation is problematic. } \\
\text { Isuggest making this sentence a topic sentence of the whole } \\
\text { paraphraph as you seem to be developing its idea in the rest } \\
\text { of the paragraph and relate the rest of the paragraph to it. } \\
\text { How about flexible labout market? } \\
\text { This is a good topic sentence, follow its example in the } \\
\text { previous paragraph. } \\
\text { See: } \\
\text { httrs:://www.macmillandictionary.com/spellcheck/british/?q } \\
\text { informatization } \\
\text { Which problems? } \\
\text { This is something completely new or have I missed } \\
\text { something? } \\
\text { Try to revise the restatement of the thesis statement by } \\
\text { making it more concise. }\end{array}$ \\
\hline
\end{tabular}

The structure of your essay meets the requirements to a great extent and you have come up with relevant ideas, their sufficient support and relevant solutions which are linked effectively and your reader can mostly follow your logic easily.

While revising the text, focus on comments above and points below:

- Try to write more formally by avoiding vague expressions (person, people, way, someone, problem) which can be effectively achieved by c.g. using passive voice or other impersonal structures or specific nouns. Also, be more specific and try to replace verbs to be or to have with action verbs, where relevant. http://www.eapfoundation.com/writing/style/

- Some of your statements are very categorical, so using more cautious language is recommended.

- Grammar problems are often connected with using the articles, see http://dictionary.cambridge.org/grammar/british-grammar/determiners/a-an-and-the 


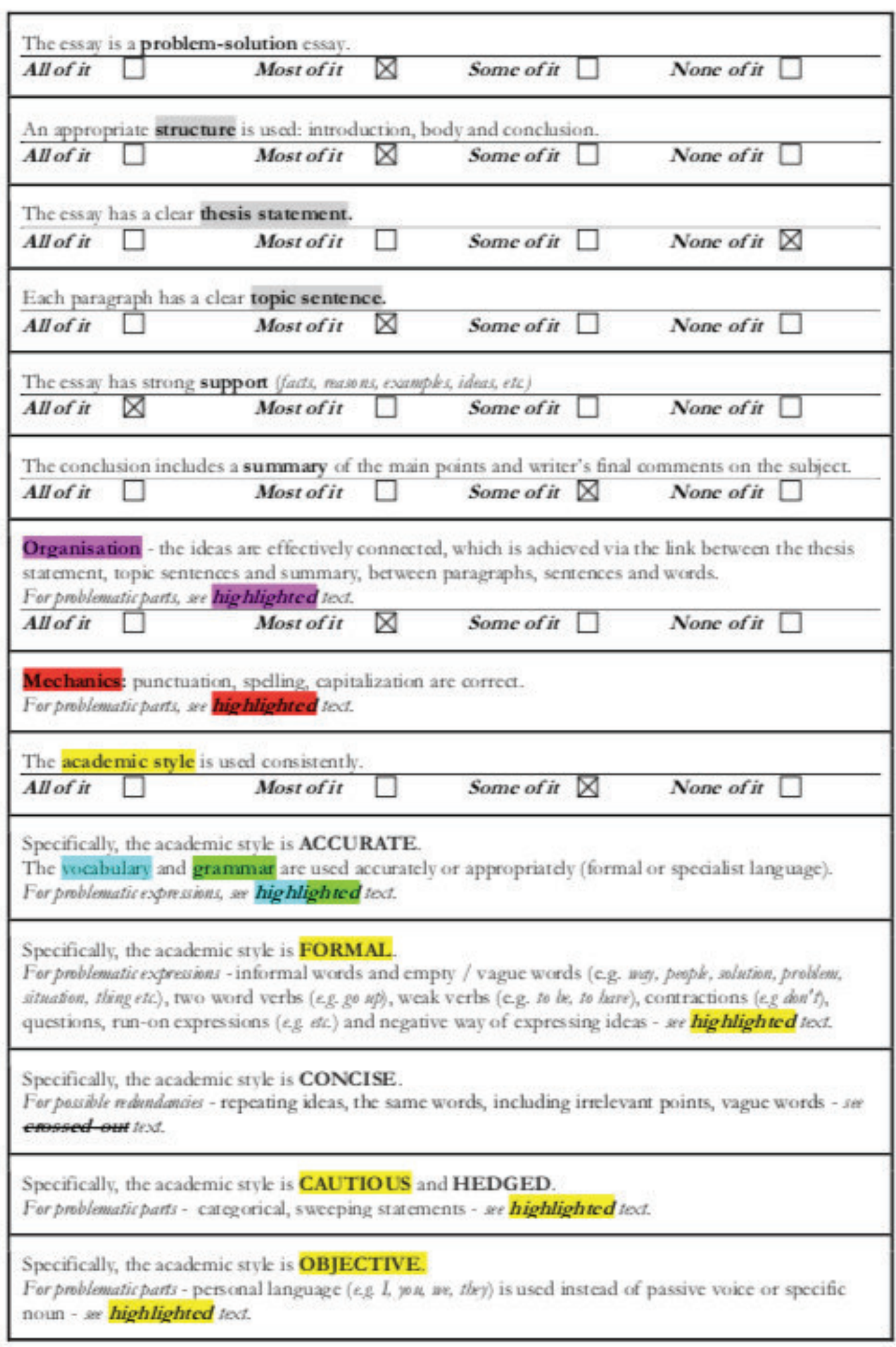




\section{Country's economy is suffering from rising unemployment|}

Unemployment is one of the most common economic issues in modern times. On a certain level, the unemployment may be tolerable and even beneficial according to some economists. If the unemployment exceeds the tolerable rate, economists and governments become concerned. High unemployment is characterised by impossibility of finding a suitable job for the significant part of the population due to insufficient supply of job vacancies. Consumption is decreasing rapidly while companies are affected by low demand for their products. As a result, employees are made redundant. While the high unemployment is a serious matter, it can be often tackled by eliminating bureaucratic burdens and investing in infrastructure.

The most serious effect of the high unemployment is growing poverty and social issues. The families without stable income have tendency to depend on unemployment benefits, which are often insufficient for the decent life. Increasing poverty can result in depressions, conflicts, drug addiction and criminality. Moreover, regions with the high unemployment are breeding grounds for social and political discontents. Affected inhabitants tend to be more radical and distrustful of authorities. As a result, populistic and extreme politicians are on the uptrend while securing political power.

Firstly, state authorities should set policies in favour of flexible labour market. Government rules, regulations, bureaucracy, high taxes and contributions burden employing new people. Governments often introduce laws and regulations, such as minimum wage or social benefits, in order to help working people, which become burden in the times of economic recession. Minimum wage is boosted by many politicians ignoring the principles of economics and reasons why companies refuse to create new jobs while keeping less productive workers.

Secondly, the governments could intervene in the economy by increasing spending. This spending requires effectivity and reasonability. Major part of the money should be spent on infrastructure investments, such as highways, railroads, informatization of public administration and research. Those investments could provide new job opportunities and bring advantageous business environment for the future economic growth. It is preferable to increase budget deficit in order to achieve future prosperity.

In conclusion, while the high unemployment may cause serious economic problems and social tension, it is often caused by reckless government policies. Nevertheless, it can be tackled by appropriate government actions and precautions. If countries desire to maintain low unemployment, they should implement policies supporting the flexible labour market and invest government funds in infrastructure and research projects irrespective of increased budget deficit.

\section{Final version}




\section{Appendix B}

\section{Peer e-feedback on the first draft in Group 2.}

\section{An appliance company is facing decreasing sales}

Ever since the management changed two months ago, the company has been facing decreasing sales. The Research \& Development department underwent strict restructuring and has not been producing any innovations. The currently used technology is out-dated which leads to the loss of competitive advantage on the market| resulting in decreasing sales. This is significant, as the decline in sales can lead to financial problems/and in the end to the company going bankrupt. Therefore, it is important to implement changes inside the company as well as find ways to improve the sales outside the company.

Decreasing sales lead to financial problems, redundancies/and loss of the competitive edge. Financial problems are likely to result in insolvency and furthermore in bankruptcy. Issues caused by not existing improvements in this fast-moving industry have caused the fall in profits. It is well known that staying up to date is crucial for keeping market share and preventing further losses.

Sales can be increased by making changes in the internal organisation. Implementing creative seminars for employees, where they can brainstorm different prospects of moving forward in research|or bringing in new people eager to incorporate their ideas into this research, $\overline{\text { might be }}$ the way to move in the right direction. Dedicated workers can focus on quality over quantity during the manufacturing process/which might bring in new, loyal customers. Cutting edge technology is one of the aspects appreciated in products that are more likely to gain competitive advantage.

Coming up with a revolutionary idea can be challenging, especially when progress in $R \& D$ department has stagnated for the last two months. Another way is to discover whether there is a different market with an interest in this product, perhaps another country where people are unable to afford the newest technology. Entering a new market where the product you are offering is missing might boost the sales and ensure that the company will survive.

In short, decreasing sales are a significant problem that can lead to the destruction of the company. Implementing the changes inside the company as well as looking for ways to boost sales outside the company is crucial in preventing the company's demise. Changes implemented inside the company are more likely to have a bigger impact on boosting the sales, although if there is an opportunity to expand into a new market| it may lead to an even bigger success. With the rapidly decreasing sales | it is essential that we take the initiative now, rather than later. 


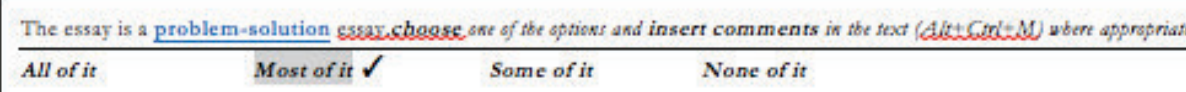

An appropriate structure is used, introduction, body and conclusion. choose ove of tbe options avd insert comments iv tbe ftxt

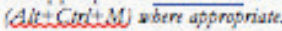

All of it $\checkmark \quad$ Most of it $\quad$ Some of it $\quad$ None of it

The essay has a clear thesis statement choose one of the optrious and insert comments in the fext (dikt CotoltM) where apporspriate.

All of it $\checkmark \quad$ Most of it $\quad$ Some of it $\quad$ None of it

Each paragraph has a clear topic sentence: choose ane of sbe options and insert comments in sbe fext (Aikt Cotoltw) wbere apporspriate.

All of it $\quad$ Most of it $\checkmark \quad$ Some of it $\quad$ None of it

The essay has strong support (facts, reasons, ecampiles, idtess, ett.)

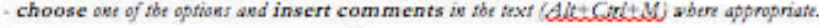

All of it $\quad$ Most of it $\checkmark$ Some of it None of it

The conclusion includes a summary of the main points and writer's final comment on the subject.

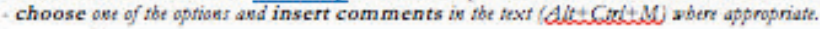

All of it $\checkmark$ Most of it $\quad$ Some of it $\quad$ None of it

Organisation - the ideas are effectively connected, which is achieved via the link between the thesis statement, topic sentences and summary, between paragraphs, sentences and words.

All of it Most of it $\checkmark$ Some of it None of it

Highlight in the text by supgested colour the parts which are not effectively linked and/or you do not understand.

Mechanica (punctuation, spelling, capitalization) Highlight in fbe fext by suggested colour the problematic part(s).

The academic style is used consistently. choose one of tbe sptions and highlight is the text by suggested colvur the problematic part(s)

All of it Most of it Some of it None of it

Specifically, the academic style is ACCURATE: the vocabulary and grammat are used accurately or appropriately (formal or specialist language). Highlight is the text by suggested colours the problematic expressions.

Specifically, the academic style is FORMAL: Highlight in the fect by suggested colour informal words and empty / vague

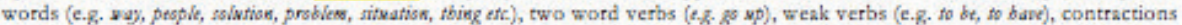
( 62 dow't), questions, run-on expressions (tat.) and negative way of expressing, ideas.

Specifically, the academic style is CONCISE: fores redundancies (repeating ideas, the same words, including irrelevant points, vague words).

Specifically, the academic style is CAUTIOUS and HEDGED: Highlight in the texf by suggested colour categorical, sweeping statements.

Specifically, the academic style is OBJECTIVE: Highlight in the text by supgested colour where personal language (e., I, yov, ve, they) is used instead of passive voice or specific noun. 